\title{
An Outlook of Housing Transformation in Dhaka City
}

\author{
Md. Kamruzzaman \\ Department of Civil Engineering, Rajshahi University of Engineering \& Technology, Rajshahi 6204, Bangladesh
}

\begin{abstract}
This paper contributes to the view that urban housing in most cities in developing countries is different in nature and more extent than that operative in developed countries. It addresses the emergence of multi-storied apartments through transformation in residential areas in Dhaka, one of the populous cities in the world and largest metropolitan region in Bangladesh, with a particular reference to a study conducted at Rupangar Residential Area. It identifies the key forces and processes underlying Dhaka's residential transformation and the advent of multi-storied apartments. Fragmentation of functions and the uses of building stocks in relation to the socio-economic aspects with local conditions were sought in the survey. The increasing housing demand is essentially fulfilling by multi-storied apartments and steadily transforming the landscape and lifestyle of huge urban dwellers in Dhaka. It reveals from the study that apartment living gains much popularity and the dominance of informal apartments over formal apartments is more evident. More distinctly, piecemeal apartment development by the informal developers provides affordable shelter to the highest segment of city dwellers and Rupnagar presents a reasoned scenario urban housing transformation in the capital of Bangladesh.
\end{abstract}

Key words: Apartment, Dhaka City, housing transformation, piecemeal construction.

\section{Introduction}

Dhaka is the nucleus city of Bangladesh and has come to be known as one of the mega cities of the world. The city in 2010 had over 16 million people for the larger conurbation and 10 million people within the central city area. The quick growth of population of Dhaka has been caused by high rate of in-migration, territorial expansion and natural growth. As housing cannot keep pace with the population increase, the city has experienced tremendous housing lack since 1970s. Phenomenal growth of the city population is dominantly contributing to the dynamic changes in residential areas. It is a deplorable fact that residential areas have lost much of their residential character in order to cope with rapid urbanization. The traditional urban housing form in Dhaka has undergone many radical transformations over the past few decades. The traditional fabric of the city has either been damaged, remodeled or has disappeared entirely. Architecturally significant buildings that are fifty to hundred years old,

Corresponding author: Md. Kamruzzaman, Ph.D., research field: urban housing. E-mail: kzaman93@gmail.com. representing their time, and located in the older part of the city, have now become obsolete primarily because of economics [1]. Thus the increasing housing demands are being fulfilled essentially by multi-storied apartments. The traditional dwelling custom has changed in different orders from the native origin. The concept of living in multi-storied apartments is something that is ordinarily not ingrained in the cultural experience of most Bangladeshi. It is a new experience for many people to live in apartments and maintain their life style, thus changing the urban and social fabric from the classic single storied independent house, to sharing smaller units of space side by side with numerous other families.

Based on this background, the objective of this paper is to identify the state of transformation in residential areas, the key forces to develop multi-storied apartments, a popular dwelling structure at present, and the adaptive alterations made by the developers in providing housing. The study examines how, why and when apartments, a western housing model, came to take place to the city of Dhaka, 
replacing the earlier house forms during the last two and half decade and remain a popular housing form at present. This will not only fill in a missing gap in the housing history of Dhaka, of which there is a shortage of research, but also provide an opportunity to make a new visual approach to the state of city's dominant housing types and reflect on the residential culture. This paper will analyze and discuss how local people develop modern housing in the indigenous construction style of the city of Dhaka, Bangladesh.

Housing is produced by private or community efforts in cities and villages in Bangladesh. People are forced to depend, in a large part on private sectors for their housing solutions in most urban areas of Bangladesh [2]. Self-help, piecemeal housing developments have penetrated deep within urban centers, surfacing through spot redevelopment of lots and embedding themselves in the urban fabric. It is an integrated hybrid of contemporary technology, new forms and reinterpreted traditional elements. It can be bland, awkward or whimsical yet is always rational, practical and expedient. Despite similarities of forms and symbols; the array of physical elements, proportions, and motifs create a distinctive regional identity for housing in Bangladesh. The legitimacy of the quest for better living conditions cannot be denied and excluding self-help piecemeal housing from the equation, the lack of housing can loom much larger that it ought to. The contributions of piecemeal developers cannot be ignored and the significance of this sector has yet to be addressed. Thus the purpose of this paper, therefore, is to outline techniques or production mechanisms for the supply of housing from indigenous households in urban areas in Bangladesh.

\section{Research Methodology}

In this study, four neighborhood areas of the RRA (Rupnagar residential area) in Mirpur, Dhaka was selected for investigation to identify characteristic features of transformation and physical growth in self-help housing developments. Selection of the area to be studied is guided by three general principles. The first principle is to ensure that the area represents a typical type. The second is to consider areas which are newly developed where culturally-rooted housing construction styles can be found. Finally, it is important to ensure that current popular housing types have been constructed in the area. A great majority of the urban population in the city of Dhaka lives in settlements where they manage to build and maintain their habitats. The characteristics of the RRA meet the three major criteria and are found to be an appropriate example of housing developments within a time span of 25 years. This enables us to better understand the prevalent housing construction style.

The study is based primarily on data from small scale interviews of 50 owner-builders, census materials, and a survey of 1,089 housing plots conducted in 2007. The 50 owner-builders were selected randomly from four neighboring areas in RRA. A questionnaire consisting of 135 structured questions was directed at household heads or their representatives, i.e. the owner-builders. Physical observations of all housing plots in the study area were undertaken in order to determine housing types, construction types, building materials, providers, building height, no. of dwelling units and finally, development length. Materials from other secondary data have also been cited. This study intends to undertake the retrieval of prevalent construction techniques that city-dwellers often adapt in their housing projects and remain consistent from the supply end. Existing literature in the field of self-help housing has not widely focused on piecemeal construction and has prompted this study to uncover facts, particularly in the context of multi-storey apartment development.

\section{Study Area}

It is helpful to first outline a few features of the study area that are pertinent for understanding issues 
of housing development in these settlements. To ease the housing problem in Dhaka city, the NHA (National Housing Authority) took up the Rupnagar project in 1982 on 35 hectares of land divided into 1,200 plots of different sizes, located at Pallabi in Mirpur, about $6 \mathrm{~km}$ from the city center (Fig. 1). Of these, 31 plots were kept designated as commercial in the project profile in order to fund the project without government funds. Rupnagar is a planned residential area; it contains plots earmarked for schools, colleges, park, hospital, lake, shopping complex and other civil amenities. The government developed these areas and allotted them to the people, mostly from the middle class. The whole study area was divided into 4 parts in order to simplify the analysis of the development pattern. Part 1 included the plots between roads 1 and 10; part 2 those between roads 11 and 16; part 3 those between roads 17 and 23, and part 4 those between

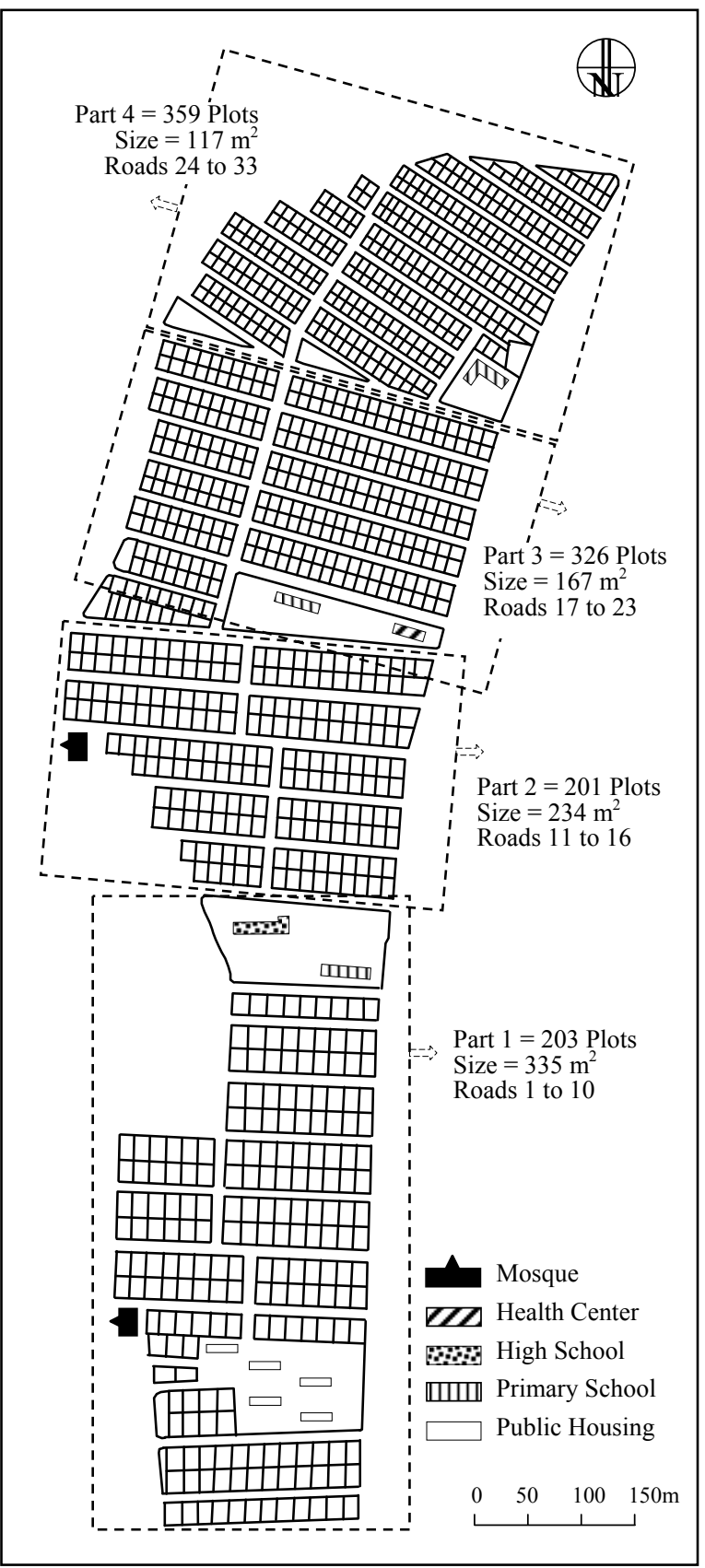

Fig. 1 Study area (1,089 plots surveyed). 
roads 24 and 33 (Fig. 1).

\subsection{Plot Size and Orientation}

The plot sizes of these projects were examined and found to range between 117 and $335 \mathrm{~m}^{2}$. In part 1, all plots were $335 \mathrm{~m}^{2}$ in area. The plots in part 2 were 234 $\mathrm{m}^{2}$ in area, with the exception of a few corner plots. Plots in part 3 were $167 \mathrm{~m}^{2}$ in area, and those in part 4 were $117 \mathrm{~m}^{2}$. The minimum plot size was $117 \mathrm{~m}^{2}$ (in part 4), while the maximum plot size of $335 \mathrm{~m}^{2}$ appeared in part 1 (Fig. 1). The typical plot was rectangular in shape and lay along the N-S axis, with its house built along the E-W axis, thus avoiding the direct sunlight from the east and west and capturing the breeze.

Regarding plot sizes, one can guess-there is a clear tendency towards reducing plot sizes. This can be taken as evidence that the issue of optimum space requirements has not been yet been fully addressed. This fact might be the outcome of the mechanical re-adoption of old designs without revision in new projects. When the RRA project was launched by NHA in the early 1980s, Dhaka was not densely populated and land was available at reasonable prices. Recently, due to rapid urbanization and its eventual pressure on residential lands for housing in Dhaka, NHA has shifted its strategy to providing apartment units rather than providing land.

\subsection{Gridiron Pattern}

In RRA, a rectilinear gridiron pattern has been adopted as the housing pattern. Plots are arranged along the main road at inclines of about 10 degrees in part 2, 15 degrees in part 3 and 30 degrees in part 4, with respect to the $\mathrm{N}$-axis. This, however, does not seriously affect heat accumulation or natural ventilation. The regular, rectangular forms, devoid of acute angles and redundant spaces, ensure the maximum utilization of the land. The simplicity of the patterns helps residents to form clear mental images of the neighborhood so that residents are seldom lost or confused about their locations at any point within the area. The simplicity also facilitates the design and execution of infrastructure items, especially as a result of the uniform optimum gradients in underground works, which make their provision and maintenance more convenient. The gross density of the RRA was about 1,925 persons per hectare. No reliable figures are currently available for housing density in Dhaka. Population density increased in order from part 1 to part 4.

\section{Piecemeal Construction of Apartments}

Piecemeal construction is a construction style wherein the buildings are designed for their final constructed size, but within which the construction takes place incrementally over time. Homeowners generally move into semi-finished buildings and then gradually continue the construction according to the choice, need and affordability. The straightest answer regarding the reason behind the prevalence of this type of construction is a lack of external finance meeting the construction costs. It is not within the scope of this paper to cover the entire range of causes behind the evolution of the type of construction used in indigenous housing of the region, thus the focus in on construction styles only.

\subsection{House Types in the Construction Phases}

In order to assess different construction phases, it is necessary to define the different house types that households often construct before beginning apartment construction. For this purpose, housing forms can be defined as: (a) temporary; (b) semi-permanent; and (c) permanent house (apartment). The general tendency of most households is to withstand possession of the land first. Thus the households build some form of a temporary structure in order for the tenants to ensure land possession. Most tenants, in this case are slum dwellers. They pay a lump-sum rent or sometimes stay on a free-hold basis. Temporary houses are locally known as kutcha 
houses. Kutcha houses generally have an earthen plinth with bamboo (sometimes timber) posts and a wall and roof made of temporary materials. The walls are made of straw, jute stick, mud, and un-burnt bricks. Roofs may be made from thatch-rice, wheat, maize straw, or catkin grass, along with split bamboo. In the study area, the highest percentages (10\%) of temporary houses are found in Part 1 area where the plots are of a large size (Fig. 2).

Semi-permanent houses are locally known as semi-pucca house. It has a shallow brick foundation with brick soling and ordinary floor finish. Walls are often built with brick or CI sheet. Roofs are with CI sheet with timber framed or steel angle framing in some cases. Generally, the workers have no formal training. Masons are trained by their seniors. The owners are the architect and masons are the engineer for this type of housing. The houses are L-shaped or U-shaped with a central courtyard ensuring maximum utilization of land (Fig. 4). A typical semi-pucca house is comprised of 6 to 8 rental units. This is a very popular form of housing as there has huge demand for rental units in all four areas of the study. The rental income in a semi-pucca house and an apartment has no significant difference while the investment cost of the latter type is quite large. Thus, the households often build this housing type and then accumulate a rental income for further investment in building apartments. The presence of this type of housing in large numbers in four areas of study reveals this fact (Fig. 2).

Permanent houses are widely termed as pucca house and most often are meant as an apartment. In the study area, apartments may be classified in two different structural forms. The first type is a load-bearing brick structure and the other is a RC (reinforced concrete) frame structure. Traditionally, a 10 inch $(25.4 \mathrm{~cm})$ brick wall is used as the load-bearing wall in the first type and a 5 inch partition wall is used in the latter type. Roofs, in both the forms are constructed with $\mathrm{RC}$ and floors with mosaic tiles according to the ability, choice and motifs of the households. Apartments made with a load-bearing brick structure are gradually disappearing because of their unsuitability to vertical extension. In the surveyed houses, less than $5 \%$ are apartments with a load-bearing structure. Apartments are the most preferred housing option in the study area. As in the Fig. 2, the highest percentages (61.7\%) of multi-storey apartments are developed in part 3 area. Average $49.4 \%$ of all housing plots in the RRA are developed with multi-storey apartments.

\subsection{Apartment Construction}

The buyers of the plots in RRA belong to the middle class. They own the plots at a subsidized rate through the government site and service scheme. Thus the land cost was not a big burden to the households

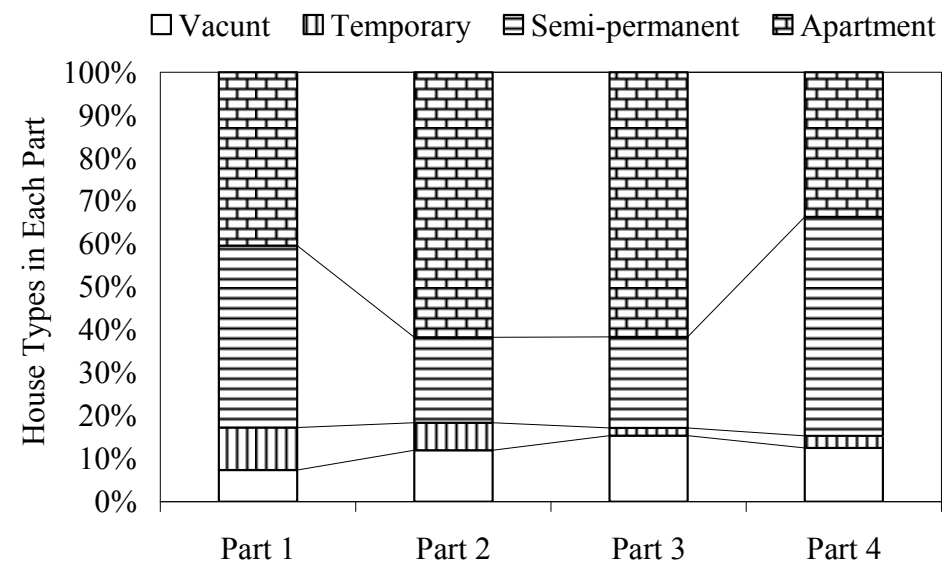

Fig. 2 Different house types in each part of the RRA. 
as compared to the construction costs. The entire financing in order to meet construction costs at different stages of construction is managed by the households with their own savings, informal loan from relatives/friends, and selling assets from rural origin. The long term goal of the households is a monetary return on investments through the addition of rental units. Almost all the interviewee households $(90 \%)$ respond that they prefer investments on housing in order to ensure decent housing within the city, income generation and to secure a source of income at the later stages.

The households have perfected prototypical layouts that permit a variety of incremental transformations. The key elements ensuring this versatility are:

- A building system which can accommodate additions and repartitioning. A reinforced concrete frame with brick or hollow block infill is the most widely used structural system (95\%). It is cost-effective in terms of the desired level of safety, durability, flexibility and ease of maintenance.

- A staircase to future upper floors conveniently located relative to street access in order to allow internal partitioning of the floor area into independent units.

Thus the households choose multi-storey apartments built with RC frame structure which fosters vertical extension and internal partitioning to provide further rental accommodation.

Households contract out construction to workers in the building trades. They retain control of the rate of build up, set the priorities, choose from alternatives and decide on the sequencing of works. The workers freely replicate, adapt and blend building techniques and styles. The choice of materials and systems is dictated by economy, practicality and expediency. The choice of motifs and colors is determined by the preference of both the builder and tenants. They share a dislike of old-fashioned styles and a conscious admiration of the new.

An illustration of the complete piecemeal construction phases which exist in the surveyed plots is shown in Fig. 3, though this omits some other micro-phases of construction, for reasons of simplicity. Households generally provide a boundary wall (phase a) soon after purchasing and finishing the land registration process. It involves no significant construction works or experience since the process is limited to brick work. No interviewee households were found who have not built a form of temporary or semi-permanent structure after purchasing the land. The slum-dwellers often build temporary housing that the landowners accept in order to retain the possession of the land. In most cases, households construct semi-permanent structures (phase b) which take less capital but generate a handsome rental income (Fig. 4). In this phase, the construction time, investment and households gain in construction skills are little increased (Fig. 3). In the surveyed plots, $42 \%$ of housing structures in part 1 area, $20 \%$ in part 2 area, $21 \%$ in part 3 area and $51 \%$ in part 4 area are semi-permanent housing (Fig. 3). Semi-permanent structures in the whole study area are, on average, $33 \%$ of all housing structures.

Generally the households take some breathing time before starting the foundation works of apartments. The principle is to accumulate sufficient capital from rental income through semi-permanent housing and then further investment in apartment construction. Thus semi-permanent houses may be treated as stepping stones towards the building of apartments. The investment recovery time is less and hence further income helps them to build apartments. Almost all the households (99\%) plan to build their apartments with 6-storys or with a maximum permissible height as stated within building bylaws. Thus there needs to be a strong foundation which is often in the form of deep (pile) foundations. Cast-in-situ piles are widely used which involve good investment as well as construction time. Thus in phase $c$, the households acquire quite good construction skills include sub-soil investigations and foundation constructions. After completing the foundation works, the households raise 


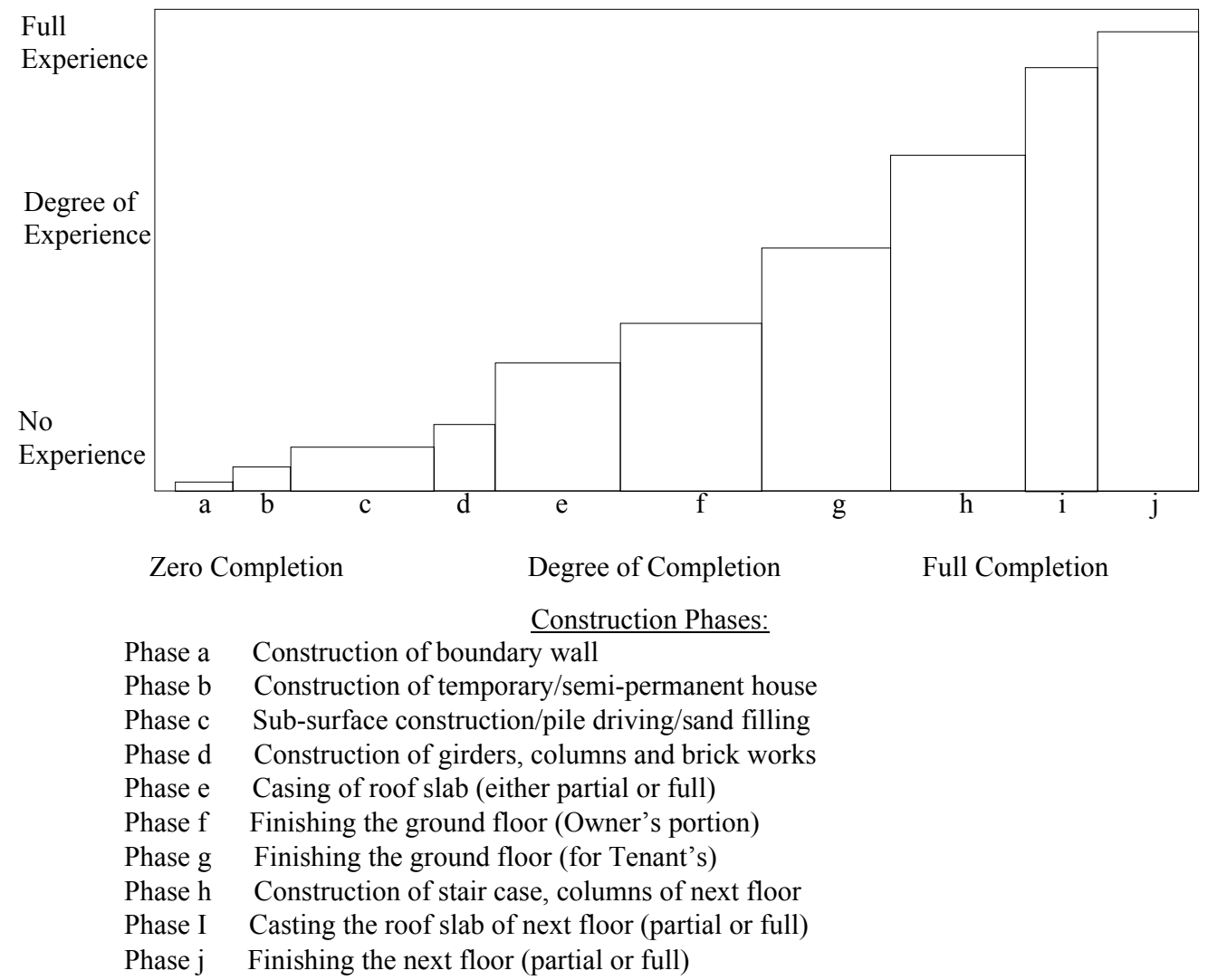

Fig. 3 Typical model of piecemeal construction.

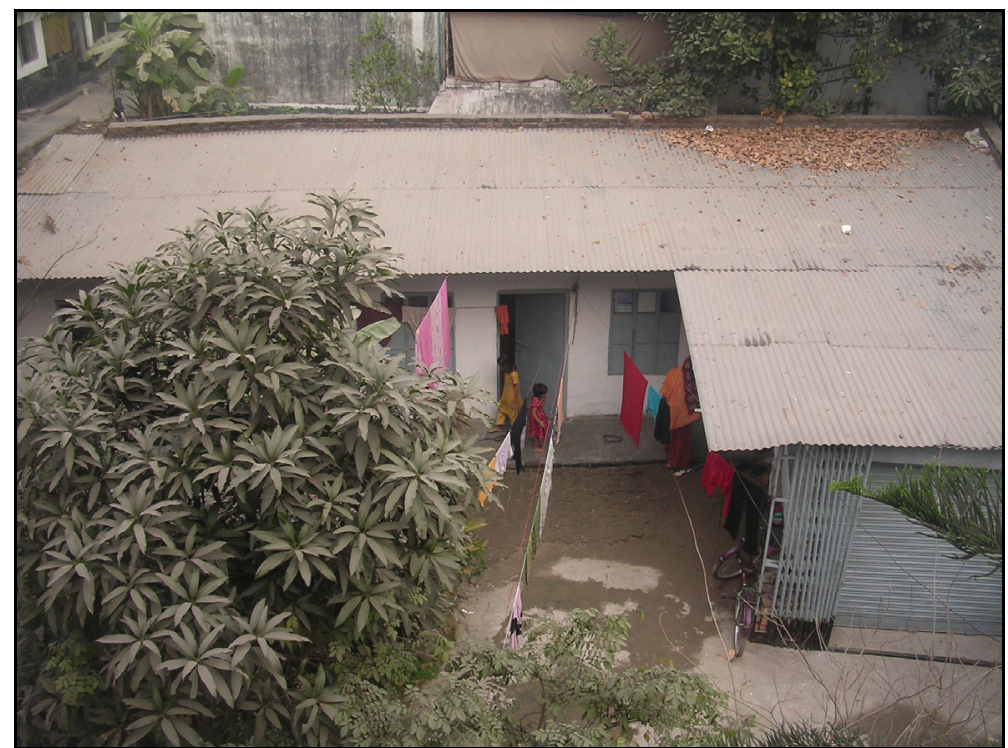

Fig. 4 L-Shaped semi-permanent house.

the land up to plinth level (about $0.5 \mathrm{~m}$ higher than maximum flood level) by sand filling.

In phase $d$, the households start to build grade beams, columns and brick works. Generally, people try to cast the roof slabs soon after completion of the brick works. Depending upon affordability, practicality and expediency, people decide to cast whole or partial roof slabs at phase e. Within the study 
area, both of the following were common practices: (1) casting half of the roof and quickly finishing the interior and (2) casting the whole roof and then finishing the interior over a longer period of time. After casting the roof slabs, the owners first move into their semi-finished houses and gradually complete the remaining work by self labor (phase f). During the next stage, the owners complete the remaining portions of the same floor for their tenants who are then invited to move in (phase g). The households then take more time for further construction. During this downtime, households minimize their financial transactions and prepare for next construction.

After a good interval, in phase $\mathrm{h}$, people start by casting staircases, columns and brickwork for the next floor (Fig. 5). As usual, households decide whether to cast the whole roof or just half based upon their local situations (phase i). As the interior finishing work require additional financing, people often do this incrementally (phase $\mathrm{j}$ ) and an incomplete first floor is seen in Fig. 6.

Again, given favorable situations and time, households continue constructing subsequent floors (Fig. 7). Meanwhile, the households attain good construction skills and attain bulk rental income, which they utilize to construct subsequent floors, as seen in Fig. 8. In later stages, construction speeds are faster than in the initial stages due to the broader construction skills of the owner-builders and well known track to informal finance. The households continue construction until the final floor, as designed in the master plan. Finance remains the main constraint on construction speed. In Fig. 9, two buildings are compared in order to differentiate the outcomes from piecemeal and non-piecemeal construction. Owner-builders of different educational, professional, social backgrounds gradually acquire construction skills during the construction of their buildings and were found to be adequately satisfied and experienced at the end of construction. Thus self-help piecemeal construction remains a popular housing construction style in Bangladesh.

\subsection{Timeframe of Piecemeal Development}

It is a little tricky to outline any time frame or to break entire construction works down into specific incremental steps over time, which can help determine the time required to complete the construction projects. The fuel for construction is money, and hence construction speed depends directly upon the availability of finances.

Households manage the finances underpinning construction projects in the face of variable and individual circumstances. Thus construction time varies widely from household to household. An empirical sequence of construction with time is outlined

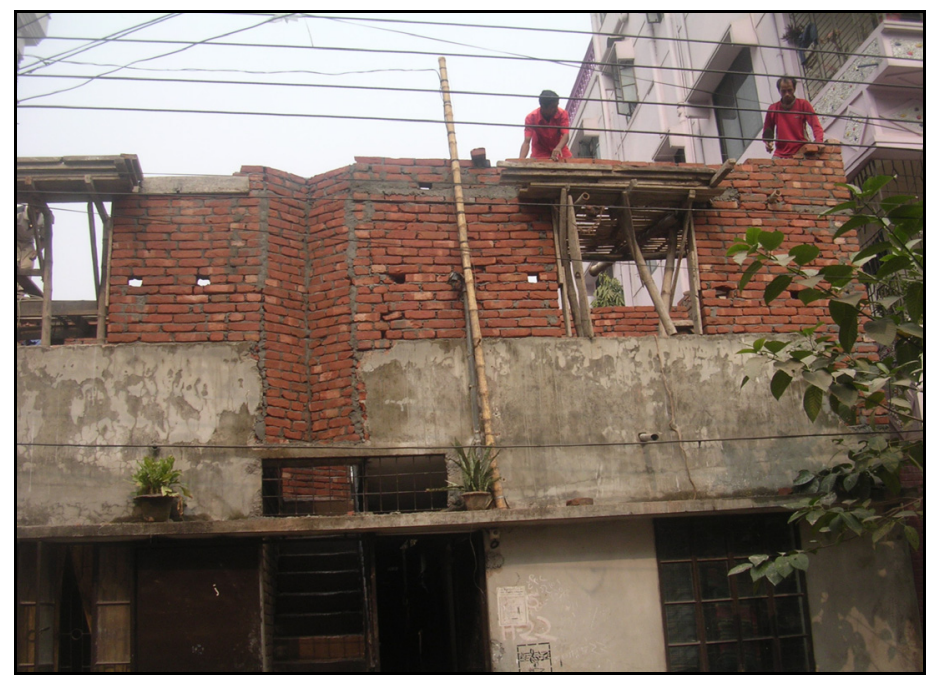

Fig. 5 Brick masonry at 1st floor after completion of ground floor. 


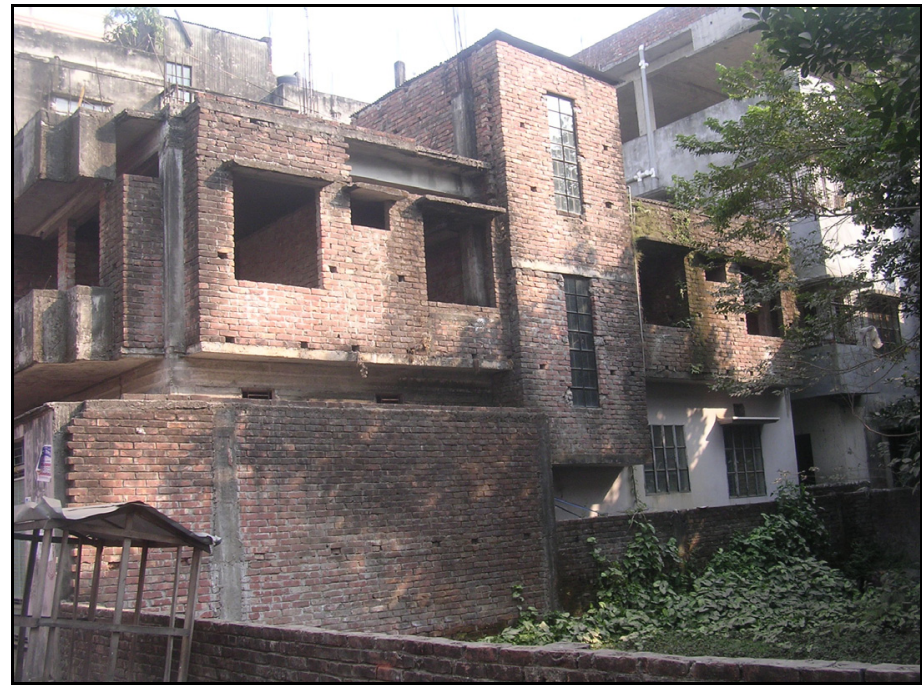

Fig. 6 Incomplete 1 st floor (brick work \& $\mathrm{RC}$ roof).

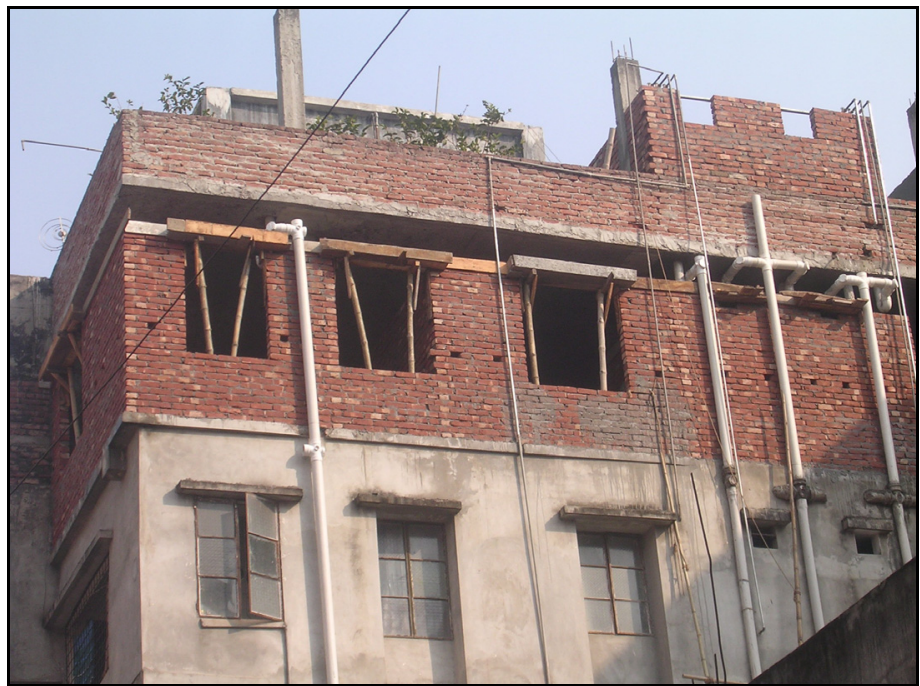

Fig. 7 Incremental addition to 2nd floor.

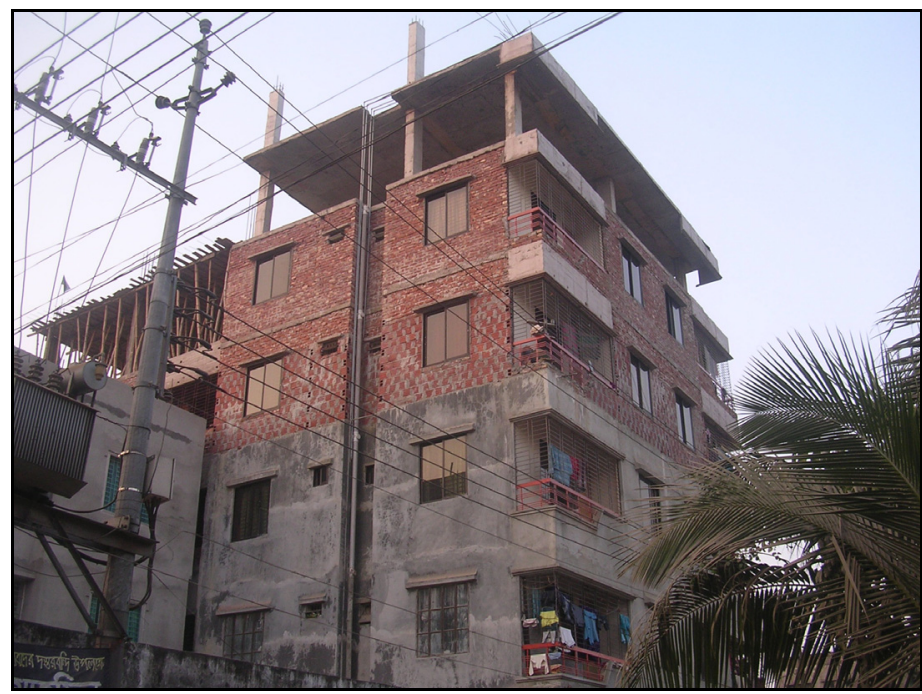

Fig. 8 Incremental addition of 3 rd, 4 th and half portion of 5th floor. 


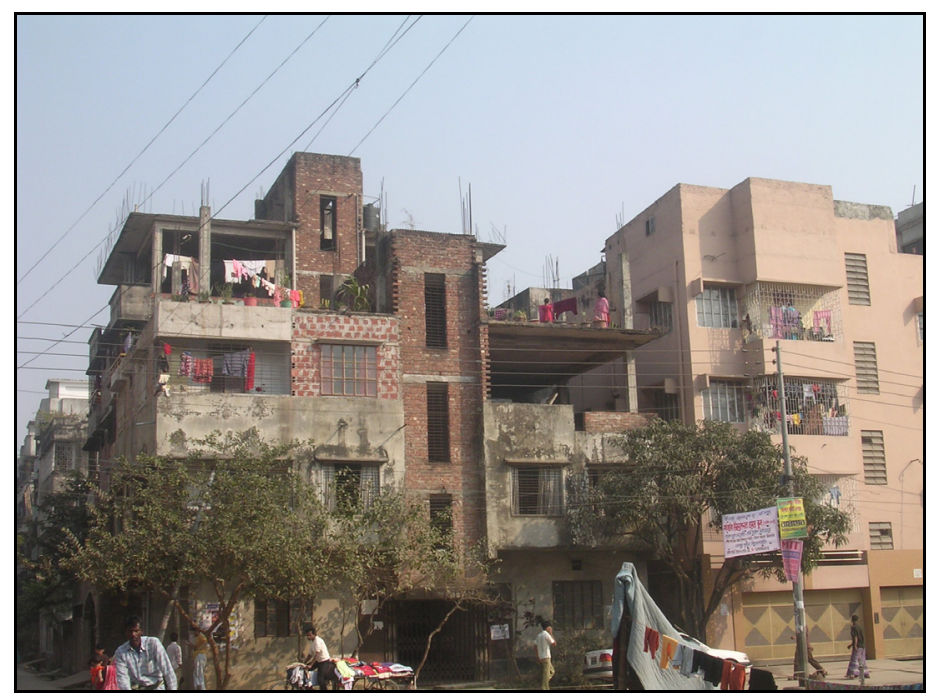

Fig. 9 Left: piecemeal development \& right: complete development. Source of photographs: field survey.

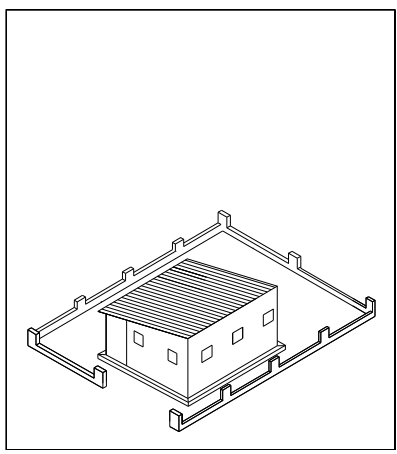

1982-Semi-permanent

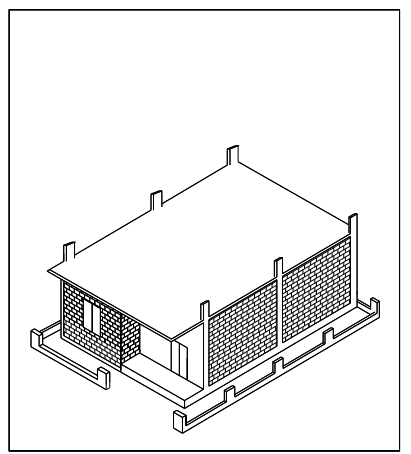

$1991-1$ st Story

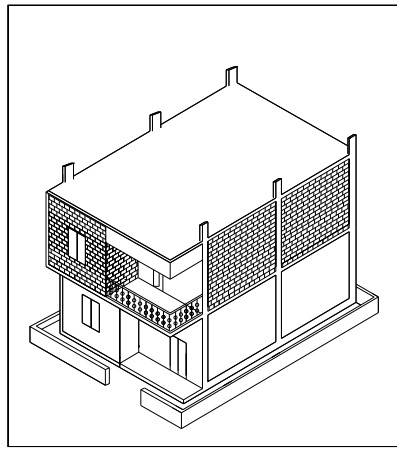

1995 -2nd Story

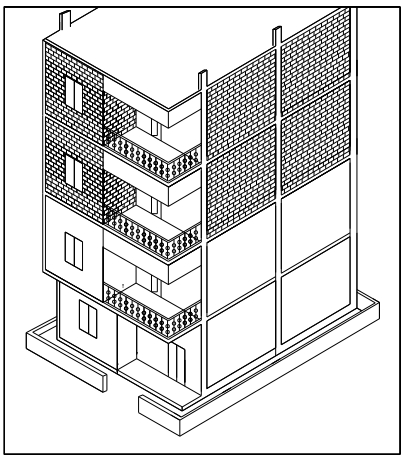

$2005-3$ rd \& 4th Story

Fig. 10 Development timeframe of typical piecemeal construction.

in Fig. 10, taking Mr. Golam Mohammad's house in part 3 as an example from among the 1,089 surveyed plots. Mr. Mohammad bought his plot in 1982 and had constructed 4-story apartment by 2005 . Thus, it took him a total of 23 years and he has no desire to perform additional construction. Examples from other households show no significant disparities with this example and an estimated 20 to 25 years is needed to complete a project.

\subsection{Piecemeal Developers}

Multi-story apartments are being built by the public sector, formal private developers and self-help owner-builders in the study area, and the details of the three providers' development figure are presented in Fig. 11. In the study area, only 5 public apartments were found in part 1 area. In the other three parts, there were no public apartments. Good numbers of private formal developers' apartments were found in part 1 area rather than part 2 and part 3 (Fig. 11). This is due to the inability of the owner-builders to build apartments on large plots with their own finances, who thus sold land to the formal developers to build apartments. Self-help owner-builders were the largest housing providers in the study area. About $92.6 \%$ of all apartments in RRA were built by owner-builders; and in smaller plots, this figure was above $98 \%$ (Fig. 11). These self-help owner-builders included piecemeal developers and non-piecemeal developers and are further analyzed in Fig. 12. As a whole, piecemeal developers contributed $71.1 \%$ of the apartments in RRA, while $21.5 \%$ belonged to 
non-piecemeal developers (Fig. 12).

Fig. 13 is an attempt to evaluate the piecemeal developers' overall contribution to housing within the study area. It is evident from Fig. 13 that buildings of moderate height in relatively smaller plots had the maximum piecemeal development rate. For example, in part 3, four-story apartments were most prevalent. In the same context, Fig. 14 demonstrates that the self-help non-piecemeal developers had different growth tendencies. For them, taller buildings on large plots were preferable. Six-story apartments made up about $58 \%$ of all non-piecemeal apartments and were common in part 1, part 2 and part 3 as shown in Fig. 14. In the study area, about $80.3 \%$ of all housing plots included piecemeal construction techniques including semi-permanent structures, and $75 \%$ of the total dwelling units were developed mostly as rental accommodations.

$\square$ Public Sector $\mathbb{0}$ Formal Developer 曰 Self-help Owner-Builder

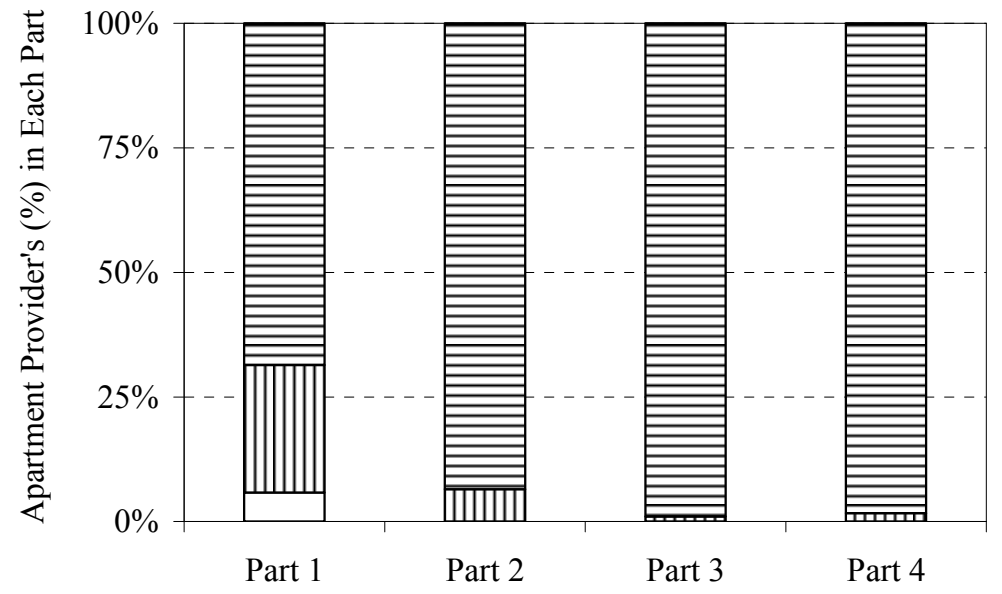

Fig. 11 Apartments provided by the different providers in RRA.

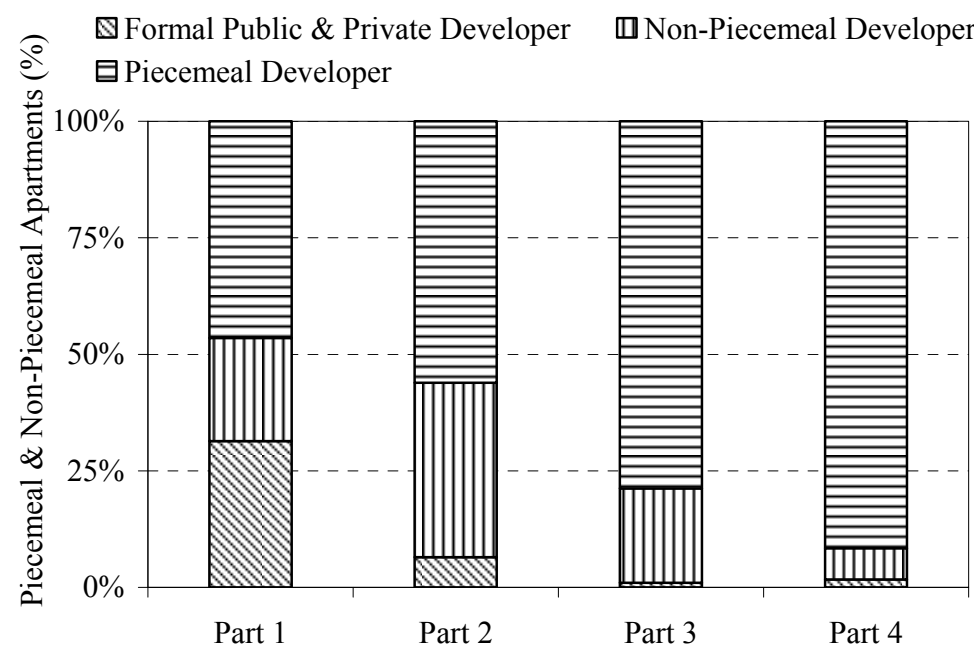

Fig. 12 Apartments provided by piecemeal \& non-piecemeal providers. 


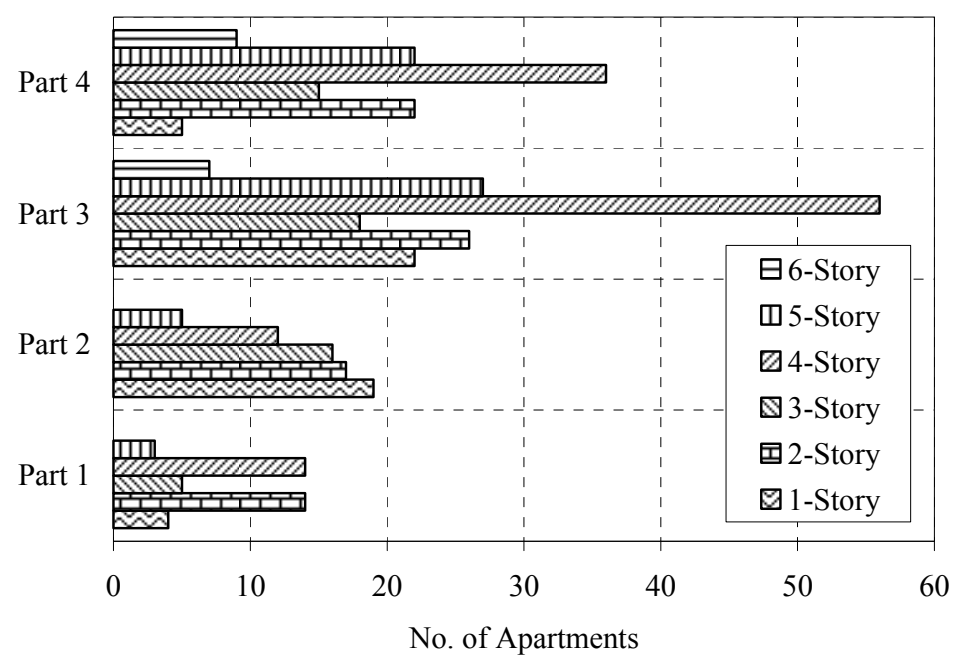

Fig. 13 Apartments of different heights \& numbers—provided by piecemeal developers.

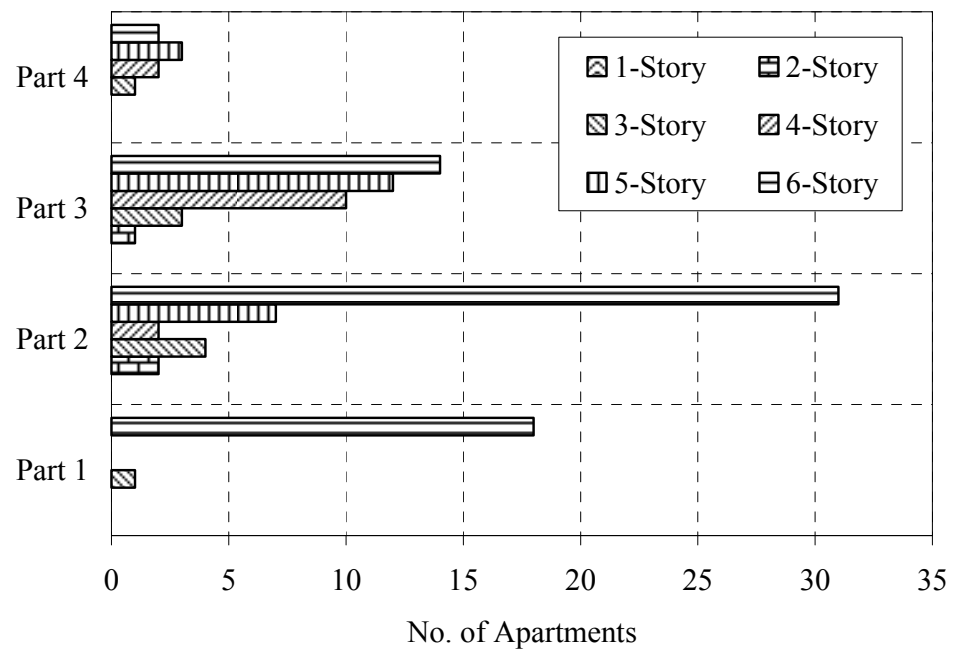

Fig. 14 Apartments of different heights \& numbers—provided by non-piecemeal developers.

\section{Conclusion}

The production of public housing is far too little and too slow to make a dent in the housing shortage afflicting most households in Dhaka. The sharp inflation in construction costs has eroded prospects of increasing affordability and added more stress to their housing solution. In these critical situations, indigenous people solve their own housing problems in their own styles. The main object of this paper has been to provide detailed information on the indigenous construction style for building modern apartments, giving examples from a Bangladeshi city and centering on the physical transformation process in the context of apartment development. Based on the above analysis and discussion, the following conclusions can be drawn.

Self-help housing is the main form of housing development in Bangladesh. The study area was a newly developed area, all of whose houses were built within the last 25 years. The relatively smaller plots in the study area were found to have high development rates, whereas the larger plots had slower growth. This was due to the people's inability to support the costs of construction on large plots. About $90 \%$ of all apartments were produced through self-help efforts, 
including piecemeal and non-piecemeal construction processes.

In the self-help, piecemeal construction process, people used to first build semi-permanent housing on their plots. They then allowed a long period of time to elapse before starting apartment construction, in order to save up sufficient money from the rental income derived from the semi-permanent housing. Thus semi-permanent housing acted as a ladder to apartment building. The construction project as a whole could be split into several smaller works and the owner-builders build their apartments gradually, simultaneously gaining construction skills, and kept on constructing until the completion of their projects. Owner-builders constructed their own dwelling units first and moved into the semi-finished apartments. Thereafter, they constructed additional units for rental use within the confines of their affordability, practicality and expediency. In later stages, construction speed was faster than in the initial stage due to their having gained construction skills and well known source of informal finance. At the end of construction, owner-builders were found to be adequately satisfied and experienced. Thus, self-help piecemeal construction is the most widely-practiced housing construction style in Bangladesh.

About $75 \%$ of all dwelling units are provided by piecemeal developers, mostly as rental accommodations. Within the prevailing difficulties, this sector holds the role of the single largest housing provider in the study area, and has become a popular form of housing construction.

Due to the lack of external financial support, people used to construct their houses according to their own financial abilities. Obviously, the energy for housing supply is slower and thus progresses incrementally. Supply speed can be increased if external finances are fed into the supply chain.

It takes nearly 20-25 years to complete a house according to its master plan. Obviously, completion largely depends on affordability and other socio-economic characteristics of the owner-builders.

The process RRA developed is a demand driven phenomena. There is no immediate panacea for the problems of promoting housing supply, and the sustainable utilization of self-help energy has the potential to produce promising results in cities in Bangladesh. It may offer a possible source of recovery from the decline of culturally-rooted building practices and renew the power of people to be intimately involved with and control the process of creating dwellings for habitation.

\section{References}

[1] Ahmed, N., and Khan, N. 2004. "Evolution of House Form in Dhaka City." Global Built Environmental Review 3.3: 38-48.

[2] Kamruzzaman, M., and Ogura, N. 2008. "Housing for the Middle Income Group in Dhaka, Bangladesh: With a Focus on Affordability and Options." Journal of Architecture and Planning (Transactions of AIJ) 73 (627): 947-54. 